\title{
Recria de Novilhas de Corte com Diferentes Níveis de Suplementação Energética em Pastagem de Aveia Preta e Azevém
}

\author{
Alcides Pilau${ }^{1}$, Marta Gomes da Rocha ${ }^{2}$, João Restle ${ }^{3}$, Régis Estivalet ${ }^{4}$, Fábio Pereira Neves ${ }^{5}$, \\ Bruno Pereira de Quadros 5
}

\begin{abstract}
RESUMO - O experimento foi conduzido com o objetivo de avaliar a recria de novilhas de corte, sob diferentes níveis de suplementação de farelo de trigo, em pastagem de aveia preta (Avena strigosa Schreb) + azevém (Lolium multiflorum Lam). Foram utilizadas 109 novilhas da raça Charolês e suas cruzas com Nelore com peso vivo (PV) no início do pastejo de 158 kg. Os níveis de suplementação foram: SS - animais exclusivamente em pastejo; S-0,5 - animais em pastejo recebendo suplemento na proporção de 0,5\% do PV; S-1,0 - animais em pastejo recebendo suplemento na proporção de 1,0\% do PV; S-1,5 - animais em pastejo recebendo suplemento na proporção de $1,5 \%$ do PV. O período de pastejo foi de 10 de julho a 02 de novembro. O sistema de pastejo foi contínuo com lotação variável, visando manter oferta de forragem de $10 \mathrm{~kg}$ de matéria seca/100kg de PV. Ganho de peso médio diário (GMD), condição corporal (CC), carga animal (CA) e ganho de peso por área (GPA) foram avaliados. Os níveis de suplementação afetaram o GMD de maneira distinta durante o ciclo da pastagem. O GMD médio das novilhas SS, S-0,5, S-1,0 e S-1,5, durante o período de pastejo, foi de 0,751; 0,894; 0,809 e $0,936 \mathrm{~kg} / \mathrm{animal} / \mathrm{dia}$, respectivamente. O ganho de CC foi maior nas novilhas suplementadas, 0,8 pontos contra 0,5 pontos das novilhas exclusivamente em pastejo. A CA aumentou linearmente durante o período de pastejo no S-1,5, possibilitando, neste nível de suplementação, GPA superior ao SS e S-0,5. A taxa de substituição no consumo de forragem pelo consumo de suplemento e a adição no consumo total de MS foram determinantes sobre o desempenho das novilhas suplementadas.
\end{abstract}

Palavras-chave: adição, farelo de trigo, pastagem cultivada, produção animal, taxa de substituição

\section{Rearing of Beef Heifers with Different Energy Supplementation Levels on Oat and Annual Ryegrass Pasture}

\begin{abstract}
An experiment was conducted to evaluate the rearing of beef heifers with different levels of wheat bran supplementation, on oat (Avena strigosa Schreb) + annual ryegrass (Lolium multiflorum Lam) pasture. One hundred nine Charolais and Charolais crossbreed Nellore heifers, with initial weight (LW) of $158 \mathrm{~kg}$, were used. The supplementation levels were: SS - animals fed oat + annual ryegrass without supplementation; S 0.5 - animals fed $0.5 \%$ of LW/day of supplementation; S 1.0 - animals fed $1.0 \%$ LW/day of supplementation; S 1.5 - animals fed $1.5 \%$ of LW/day of supplementation. The grazing period was from July $10^{\text {th }}$ to November $02^{\text {nd }}$ with continuous grazing and forage offer of $10 \mathrm{~kg}$ dry matter $(\mathrm{DM}) / 100 \mathrm{~kg} \mathrm{LW}$. The variables studied were average daily weight gain (ADG), body condition (BC), stocking rate (SR) and weight gain per ha (LWG). The supplementation levels affected the ADG, on a different way during the pasture cycle. Average ADG wasof $0.751 ; 0.894 ; 0.809$ and $0.936 \mathrm{~kg} /$ animal/day for SS, S- 0.5 , S-1.0 e S-1.5 heifers, respectively. BC gain was higher for supplemented heifers, 0.8 points vs 0.5 points for heifers maintained only on pasture. The SR increased linearly during the grazing period, for the S 1.5 , resulting in greater LWG than for the SS and S 0.5 . The substitution rate of forage intake by the supplement consumption and the addition on total DM intake were determinant for the supplemented heifers performance.
\end{abstract}

Key Words: addition, animal production, cultivate pasture, substitution rate, wheat bran

\section{Introdução}

O uso de pastagem cultivada de inverno, no Rio Grande do Sul, é uma técnica consolidada entre os produtores rurais que buscam melhorar os índices produtivos de seus rebanhos. Nos últimos anos, com o aumento das áreas de integração lavoura-pecuária, muitas propriedades que trabalham com sistemas de cria e recria estão interessadas em reduzir o acasalamento das novilhas para idades inferiores a 24 meses. Entre os fatores determinantes desta mudança estão a necessidade de melhor utilização da área pastoril e de maior eficiência na produção de bezerros.

${ }^{1}$ Zoot. Aluno do curso de Pós-Graduação em Zootecnia- UFSM. Bolsista CAPES (alcidespilau@bol.com.br).

2 Eng. Agr. Dra ${ }^{2}$. Profa . Adjunta - Departamento de Zootecnia - UFSM. R. Tuiuti, 1554/201. Santa Maria. RS (tata@pro.via-rs.com.br).

3 Engenheiro-Agrônomo, PhD, Pesquisador Visitante/CNPq - Departamento de Produção Animal - UFG (jorestle@terra.com.br).

${ }^{4}$ Aluno do curso de Graduação em Zootecnia, UFSM (setorforrageiras@bol.com.br).

${ }^{5}$ Aluno do curso de Graduação em Agronomia, UFSM. Bolsistas FAPERGS e CNPq (setorforrageiras@bol.com.br). 
A suplementação em pastagem cultivada no período hibernal durante a recria, nestas condições, torna-se uma alternativa de fundamental importância. Para ser acasalada aos 14 meses, entre a desmama e o acasalamento, a novilha deve realizar ganho correspondente a $25 \%$ de seu peso adulto, pressupondo que tenha em torno de $40 \%$ deste peso, por ocasião da desmama, e deve atingir 65\% no acasalamento (Rocha \& Lobato, 2002).

O uso da suplementação energética em pastagens tem como principal meta melhorar o ganho de peso individual dos animais e, por conseguinte, aumentar a carga animal por hectare em relação à utilização exclusiva da pastagem. A substituição de parte do consumo de forragem pelo consumo de suplemento pode elevar a capacidade de carga até valores que, sem redução acentuada do ganho por indivíduo, possibilitem melhorar a produção animal por unidade de área (Rocha et al., 2003).

Quando o concentrado é fornecido, a redução no consumo de forragem pode ser tanto desejável como indesejável. Em condições de suplementação, novas variáveis interferem no consumo de nutrientes. Elas estão associadas às relações de substituição de forragem por suplemento e/ou adição no consumo total de matéria seca, dependendo das características da base forrageira e do suplemento (Hodgson, 1990). O conhecimento do tipo e da quantidade do suplemento energético a ser fornecido aos animais contribui para maior eficiência de utilização da suplementação.

Os grãos de cereais - milho, aveia preta e sorgo - e subprodutos da indústria (farelo de trigo e casca de soja) são fontes de energia facilmente disponíveis para suplementar bovinos em pastejo no Estado do Rio Grande do Sul. Em pastagens de alta proteína, como a mistura de aveia preta (Avena strigosa Schreb) + azevém (Lolium multiflorum Lam.), a degradabilidade do amido do suplemento adquire grande importância. O farelo de trigo com maior degradabilidade ruminal que o milho ou sorgo, provavelmente, é boa fonte de energia para bovinos em pastagens com alta proteína (Rearte \& Pieroni, 2001).

Na recria de novilhas de corte em pastagem de aveia preta + azevém, com o uso de suplementos ricos em amido, como sorgo e milho, tem-se verificado desempenho individual dos animais abaixo do desejável nos períodos inicial e final do ciclo vegetativo das forrageiras (Rocha et al., 2001; Santos et al., 2002). Suplementos com maior teor de fibra podem ser alternativa para melhorar o desempenho animal nes- tes períodos e, conseqüentemente, potencializar maior peso das novilhas ao final da utilização da pastagem. A utilização de suplementos energéticos ricos em fibra prontamente digestível parece ter efeito menos negativo sobre o consumo de forragem que aqueles com base em amido, e podem resultar em aumento no consumo total de matéria seca (Poppi \& McLennam, 1995).

Objetivou-se, com este trabalho, avaliar o desempenho de novilhas de corte em recria com diferentes níveis de suplementação de farelo de trigo em pastagem de aveia preta + azevém.

\section{Material e Métodos}

Os dados foram coletados em área pertencente ao Departamento de Zootecnia da Universidade Federal de Santa Maria (UFSM), localizada na região fisiográfica denominada Depressão Central do Rio Grande do Sul, com altitude de $95 \mathrm{~m}$, latitude $29^{\circ} 43^{\prime}$ sul e longitude $53^{\circ} 42^{\prime}$ oeste.

O solo da área experimental pertence à unidade de mapeamento São Pedro, classificado como ARGISSOLO VERMELHO Distrófico Arênico (EMBRAPA, 1999), apresentando relevo levemente ondulado, com solos profundos e de textura superficial arenosa, bem drenados e naturalmente ácidos. O clima da região é Cfa (subtropical úmido) conforme classificação de Köppen (Moreno, 1961).

O experimento iniciou-se em 08/05/2002, com término em 02/11/2002. A área experimental foi dividida em 12 potreiros com área média de 0,97 ha, totalizando 11,7 ha, e mais uma área contígua de 6 ha para a permanência dos animais reguladores.

A pastagem foi implantada pelo sistema de preparo mínimo, em 08/05/2002. A semeadura e adubação de base foram realizadas a lanço, sendo cada componente distribuído individualmente. Foram utilizados $90 \mathrm{~kg} / \mathrm{ha}$ de aveia preta, $35 \mathrm{~kg} / \mathrm{ha}$ de azevém e $300 \mathrm{~kg} / \mathrm{ha}$ de adubo da fórmula 05-20-20. Em cobertura, foram aplicados $130 \mathrm{~kg} /$ ha de nitrogênio (N) na forma de uréia, em três aplicações, sendo a primeira 35 dias após a semeadura e as demais, em 10/08 e 25/09. O período de estabelecimento da pastagem foi de 62 dias, com sistema de pastejo contínuo, sendo utilizados três animais-teste e número variável de reguladores por repetição.

Foram usadas 109 novilhas de idade média inicial de oito meses, pertencentes ao Setor de Bovinocultura de Corte e formadas pelos grupos genéticos Charolês, 
3/4 Charolês/Nelore e 5/8 Nelore/Charolês. O peso e a condição corporal médios, no início do pastejo, foram de $158 \mathrm{~kg}$ e 2,7 , respectivamente.

Os níveis de suplementação utilizados foram: SS - animais exclusivamente em pastejo; S-0,5 animais em pastejo recebendo suplemento na proporção de $0,5 \%$ do peso vivo (PV); S-1,0 - animais em pastejo recebendo suplemento na proporção de 1,0\% do PV; S-1,5 - animais em pastejo recebendo suplemento na proporção de $1,5 \%$ do PV. O suplemento utilizado foi o farelo de trigo, fornecido diariamente às 14 h. Os níveis foram calculados em base seca.

O período de pastejo foi de 10/07 a 02/11, totalizando 115 dias. Foi adotado um período de adaptação de 10 dias; os demais períodos foram de 28 dias e o último de 21 dias.

As pesagens individuais dos animais foram realizadas no início e final de cada período de pastejo, após jejum de 12 horas. O escore de condição corporal foi avaliado após a pesagem de cada animal e seguiu a metodologia de Lowman et al. (1973), com valores de 1 a 5 , em que 1 = muito magro e $5=$ muito gordo.

O controle de endoparasitas foi realizado com duas dosificações dos animais com levamisol fosfato, sendo a primeira antes de iniciar o período de pastejo e a segunda em 21/08.

O ajuste de carga animal (CA) foi realizado para manter massa de forragem (MF) de 1.000, 1.100, $1.200,1.400$ e $1.600 \mathrm{~kg} / \mathrm{ha}$ de MS nos diferentes períodos de utilização. O ajuste foi realizado da seguinte forma: CA (kg/ha) igual à MF no momento do ajuste dividida por 28 dias, somada com a taxa de acúmulo de forragem (TAD) estimada para o período subtraída a TAD necessária para atingir a MF pretendida no período subseqüente. A partir do valor encontrado, foi estimada uma oferta de forragem pretendida de $10 \mathrm{~kg} \mathrm{MS} / 100 \mathrm{~kg}$ de PV. Aos tratamentos S-0,5, S-1,0 e S-1,5 foram adicionados, nos ajustes imediatamente após a pesagem, incrementos de carga de 10; 25 e 35\%, respectivamente, em relação ao tratamento sem suplementação. Esta CA foi reajustada no decorrer de cada período para manter a MF pretendida.

A MF foi determinada no início do período de pastejo e, posteriormente, a cada 14 dias pela técnica de dupla amostragem (Wilm et al., 1944). Em cada repetição, foram realizados cinco cortes rente ao solo e 20 estimativas visuais. Para determinação da TAD (kg/ha), foram utilizadas três gaiolas de exclusão ao pastejo por repetição, utilizando-se a metodologia descrita por Klingmann et al. (1943). A medição da altura da pastagem (ALT) foi realizada a cada estimativa da MF pela técnica da dupla amostragem, medindo-se a distância do solo até a altura média do dobramento das folhas dentro do quadrado.

A determinação do teor de MS foi a partir de amostras colhidas em cada avaliação de dupla amostragem, por repetição. A amostra foi pesada e secada em estufa a $65^{\circ} \mathrm{C}$, por, no mínimo, 72 horas, até peso constante. A oferta de forragem (kg de MS/ $100 \mathrm{~kg}$ de PV) foi calculada pelo produto entre MF dividida por 28 dias e a TAD, divididos pela CA. A oferta de forragem + suplemento (OFS) foi calculada em porcentagem do $\mathrm{PV}$.

A determinação do valor nutritivo da forragem foi a partir de análise laboratorial de amostras de forragem colhidas por meio de simulação de pastejo (Gibb \& Treacher, 1976). A amostra colhida foi pesada e secada em estufa a $65^{\circ} \mathrm{C}$, por 72 horas, posteriormente processada em moinho tipo Willey e encaminhada para análise. Os parâmetros avaliados foram: proteína bruta (PB) e digestibilidade in vitro da matéria orgânica (DIVMO), de acordo com as técnicas descritas pela AOAC (1984) e por Tilley \& Terry (1963), respectivamente. O teor de nutrientes digestíveis totais (NDT) foi estimado pelo produto entre a porcentagem de matéria orgânica (\%MO) e a da \%DIVMO, dividida por 100 .

O ganho de peso médio diário (GMD) dos animais foi obtido pela diferença entre peso final e inicial dos animais-teste, em cada período experimental, dividido pelo número de dias do período de pastejo. A carga animal (CA) por período foi obtida pela soma do peso médio dos animais-teste. A este valor foi adicionada a soma do peso médio dos animais reguladores multiplicado pelo número de dias que estes permaneceram na repetição, dividido pelo número de dias do período de pastejo. A CA foi expressa em kg/ha de PV. O ganho de peso por área (GPA) foi obtido pelo somatório do ganho de peso dos animais-teste. A este valor foi adicionado o produto entre o GMD da repetição e o número de dias em que cada animal regulador permaneceu no potreiro.

O consumo de MS de forragem foi estimado a partir da fórmula: produção total de MS - MF no final do período experimental - perdas de forragem ocorridas durante o período de pastejo. Dividindo-se o consumo de MS de forragem estimado pela CA, obteve-se o consumo estimado de MS, em \% do PV.

R. Bras. Zootec., v.33, n.6, p.2104-2113, 2004 (Supl. 2) 
A taxa de substituição e de adição do consumo de suplemento sobre o consumo de forragem foi estimada a partir do cálculo proposto por Hodgson (1990), em que: substituição = (consumo de forragem dos animais não-suplementados - consumo de forragem dos animais que recebem suplementação)/consumo de suplemento*100; adição = $($ consumo total de MS dos animais suplementados - consumo de forragem dos animais não-suplementados)/consumo de suplemento*100.

O delineamento experimental foi o inteiramente casualizado, sendo cada tratamento formado por três repetições. Nas repetições, foram tomados dados de três unidades amostrais (animais-teste).

O modelo matemático referente à análise dos parâmetros estimados foi:

$$
\mathrm{Y}_{\mathrm{ijkl}}=\mu+\mathrm{NS}_{\mathrm{i}}+\mathrm{P}_{\mathrm{j}}+\mathrm{R}_{\mathrm{k}}(\mathrm{NS})_{\mathrm{i}}+(\mathrm{NS} * \mathrm{P})_{\mathrm{ij}}+\varepsilon_{\mathrm{ijkl}}
$$

$\mathrm{Y}_{\mathrm{ijkl}}=$ variáveis dependentes; $\mu=$ média de todas as observações; $\mathrm{NS}_{\mathrm{i}}=$ efeito do i-ésimo nível de suplementação; $\mathrm{P}_{\mathrm{j}}=$ efeito do $\mathrm{j}$-ésimo período; $\mathrm{R}_{\mathrm{k}}(\mathrm{NS})_{\mathrm{i}}=$ efeito da k-ésima repetição dentro do i-ésimo nível de suplementação (erro A); $\mathrm{NS}^{*} \mathrm{P}_{\mathrm{ij}}=$ efeito de interação entre o i-ésimo nível de suplementação e o j-ésimo período; $\varepsilon_{\mathrm{ijkl}}=$ erro experimental (erro B).

As variáveis estudadas foram submetidas à análise de variância dos dados e teste $\mathrm{F}$, a $5 \%$ de significância. Quando foram detectadas diferenças entre níveis de suplementação ou períodos, foram realizadas comparações de médias pelo teste Tukey, a 5\% de significância.
Em caso de interação NS*P, foi realizado teste de regressão polinomial até terceira ordem, a 5\%, considerando-se a de maior coeficiente de determinação $\left(\mathrm{R}^{2}\right)$. As análises foram efetuadas utilizandose o procedimento GLM (General Linear Models) do programa estatístico SAS versão 6.08 (SAS, 1997).

\section{Resultados e Discussão}

A Tabela 1 apresenta a massa de forragem (MF), altura da pastagem, taxa de acúmulo diária de forragem (TAD), oferta de forragem + suplemento (OFS) por período e na média ponderada. As variáveis mencionadas acima não foram influenciadas pelos tratamentos. A MF, no decorrer do período de pastejo, aumentou gradativamente de $819 \mathrm{~kg} / \mathrm{ha}$ de MS, no primeiro período, para $1.590 \mathrm{~kg} / \mathrm{ha}$ de MS, no período final. Nos três períodos iniciais, foi mantida MF inferior a $1.200 \mathrm{~kg} / \mathrm{ha}$ de MS, valor considerado por Moraes (1991) limitante ao desempenho animal. Com o manejo da MF, pretendeu-se evitar o alongamento dos entrenós e a elevação precoce do ponto de crescimento da aveia preta (Restle et al., 2000).

A OFS média foi $10 \mathrm{~kg}$ de MS/100 kg de PV, variando de 8 a $12 \mathrm{~kg}$ de MS/100 kg de PV durante o período de pastejo. O animal, em pastejo contínuo, consome sempre o estrato superior da pastagem, que, nos períodos iniciais de pastejo, apresenta maior quantidade de lâminas foliares em relação a colmos. A redução no consumo de matéria orgânica inicia-se no momento em que a altura de lâmina foliar acima da bainha atinge $5 \mathrm{~cm}$ (Ribeiro Filho et al., 2002). A MF,

Tabela 1 - Massa de forragem (MF), altura da pastagem (ALT), taxa de acúmulo diária de forragem (TAD) e oferta de forragem + suplemento (OFS) em pastagem de aveia preta + azevém para a recria de fêmeas de corte

Table 1 - Forage mass (FM), pasture height (PH), daily accumulation rate (DAR) and forage offer + supplement (FOS) on oat + annual ryegrass pasture for beef heifers rearing

\begin{tabular}{|c|c|c|c|c|}
\hline $\begin{array}{l}\text { Período } \\
\text { Period }\end{array}$ & $\begin{array}{c}\text { MF } \\
F M \\
\mathrm{~kg} / \mathrm{ha} \mathrm{MS} \\
\mathrm{kg} / \mathrm{ha} \mathrm{DM}\end{array}$ & $\begin{array}{c}\text { ALT } \\
P H \\
\mathrm{~cm}\end{array}$ & $\begin{array}{c}\text { TAD } \\
\text { DAR } \\
\mathrm{kg} / \mathrm{ha} \mathrm{MS} \\
\mathrm{kg} / \mathrm{ha} \mathrm{DM}\end{array}$ & $\begin{array}{c}\text { OFS } \\
\text { FOS } \\
\mathrm{kg} \mathrm{MS} / 100 \mathrm{~kg} \mathrm{PV} \\
\mathrm{kg} \mathrm{DM} / 100 \mathrm{~kg} \mathrm{LW}\end{array}$ \\
\hline $10 / 07-20 / 07$ & 819d & 19a & 44ab & $12 \mathrm{a}$ \\
\hline 21/07-17/08 & $977 \mathrm{~cd}$ & $16 b$ & $37 a b$ & $9 b$ \\
\hline 18/08-14/09 & $1112 c$ & $12 \mathrm{c}$ & $54 a$ & $12 \mathrm{a}$ \\
\hline $14 / 09-12 / 10$ & $1360 b$ & $15 b$ & $29 b$ & $8 b$ \\
\hline 21/10-02/11 & 1590a & $16 b$ & 38ab & $8 b$ \\
\hline $\begin{array}{l}\text { Média ponderada } \\
\text { Weighed mean }\end{array}$ & 1201 & 15 & 40 & 10 \\
\hline CV\% & 15,97 & 12,02 & 29,08 & 12,62 \\
\hline
\end{tabular}

a, b, c, d na mesma coluna, diferem entre si $(P<0,01)$.

$a, b, c, d$ in the same column differ $(P<.01)$.

R. Bras. Zootec., v.33, n.6, p.2104-2113, 2004 (Supl. 2) 
nestas condições, não pode ser colocada como fator determinante sobre o consumo de forragem, uma vez que a OFS foi mantida próxima ao valor preconizado e a altura da pastagem permitiu o pastejo seletivo pelos animais.

Na Tabela 2, encontram-se os teores de matéria seca da pastagem e do suplemento, proteína bruta, DIVMO e NDT na forragem aparentemente consumida e no suplemento. Os parâmetros descritos anteriormente não foram afetados pelos níveis de suplementação. O teor médio de PB na forragem aparentemente consumida foi de 21,1\%. Dos 115 dias de pastejo, durante 94 dias o teor de PB permaneceu acima de $18 \%$, valor seis pontos percentuais acima do preconizado pelo NRC (1984) para esta categoria animal. O elevado teor de proteína bruta de algumas forrageiras, como a aveia preta e o azevém, causa, em alguns períodos de utilização da pastagem, desperdício deste nutriente (Lupatini et al., 1998), que pode ser parcialmente evitado com energia suplementar.

A DIVMO média de todo período de pastejo foi de $54 \%$, valor 12 e $17 \%$ inferior às médias de 62 e $65 \%$ verificadas por Frizzo et al. (2003) e Pelegrini et al. (2002), respectivamente, na mesma área em anos anteriores também com novilhas em pastejo contínuo sobre aveia preta + azevém.

As variáveis ganho de peso médio diário (GMD), condição corporal (CC), carga animal (CA) e ganho de peso por área (GPA) apresentaram interação significativa entre nível de suplementação (NS) e período (P).
Constam, na Tabela 3, os valores de ganho diário médio nos níveis de suplementação utilizados durante os períodos experimentais. Houve interação tratamento $\mathrm{x}$ período. As equações de regressão são apresentadas na Figura 1.

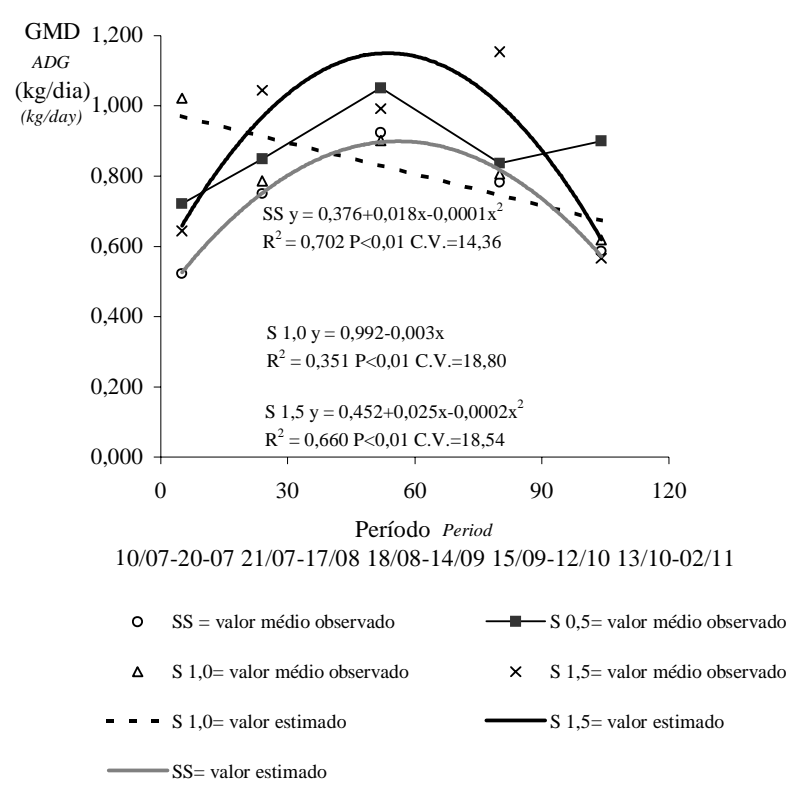

Figura 1 - Ganho de peso médio diário (GMD) de noviIhas de corte submetidas a níveis de suplementação em pastagem de aveia preta + azevém, de acordo com o período de pastejo.

Figure 1 - Average daily weight gain ( $\mathrm{kg} /$ day) of beef heifers on oat + annual ryegrass pasture submitted to different supplementation levels, according to grazing period.

Tabela 2 - Matéria seca, proteína bruta, digestibilidade in vitro da matéria orgânica (DIVMO) e nutrientes digestíveis totais (NDT) da pastagem de aveia preta + azevém e do suplemento para recria de novilhas de corte submetidas a diferentes níveis de suplementação

Table 2 - Dry matter, crude protein, in vitro organic matter digestibility (IVOMD) and total digestible nutrients (\%TDN) of oat + annual ryegrass pasture and supplement for rearing of beef heifers submitted to different supplementation levels

\begin{tabular}{|c|c|c|c|c|}
\hline $\begin{array}{l}\text { Período } \\
\text { Period }\end{array}$ & $\begin{array}{c}\text { Matéria seca } \\
\text { Dry matter } \\
\%\end{array}$ & $\begin{array}{c}\text { Proteína bruta } \\
\text { Crude protein } \\
\%\end{array}$ & $\begin{array}{c}\text { DIVMO } \\
\text { IVOMD } \\
\%\end{array}$ & $\begin{array}{l}\text { NDT } \\
\text { TDN } \\
\%\end{array}$ \\
\hline 10/07-20/07 & $12,95 b$ & $20,5 b$ & $72 \mathrm{a}$ & $66 a$ \\
\hline 21/07-17/08 & $14,92 b$ & $18,0 \mathrm{c}$ & $56 b$ & $50 \mathrm{~b}$ \\
\hline 18/08-14/09 & $14,05 b$ & $24,8 \mathrm{a}$ & $49 b$ & $44 \mathrm{~b}$ \\
\hline $14 / 09-12 / 10$ & 13,69b & $21,6 b$ & $57 b$ & $51 b$ \\
\hline 21/10-02/11 & $23,22 a$ & $14,6 \mathrm{~d}$ & $47 b$ & 43b \\
\hline Média ponderada & 15,75 & 21,1 & 54 & 49 \\
\hline \multicolumn{5}{|l|}{ Weighed mean } \\
\hline CV\% & 8,07 & 8,78 & 10,32 & 10,54 \\
\hline Suplemento & 87,43 & 15,4 & 65,5 & 62,0 \\
\hline Supplement & & & & \\
\hline
\end{tabular}

$a, b, c, d$ na mesma coluna, diferem entre si $(P<0,01)$.

$a, b, c, d$ in the same column differ $(P<.01)$.

R. Bras. Zootec., v.33, n.6, p.2104-2113, 2004 (Supl. 2) 
Tabela 3 - Ganho de peso médio diário ( $\mathrm{kg} / \mathrm{animal}$ ) de bezerras de corte em aveia + azevém submetidas a diferentes níveis de suplementação energética

Table 3 - Average daily gain ( $\mathrm{kg} / \mathrm{animal}$ ) of beef heifers on oat plus Italian ryegrass submitted to different energy supplementation levels

\begin{tabular}{|c|c|c|c|c|c|c|}
\hline \multirow[t]{2}{*}{$\begin{array}{l}\text { Tratamento } \\
\text { Treatment }\end{array}$} & \multicolumn{5}{|c|}{$\begin{array}{c}\text { Período } \\
\text { Period }\end{array}$} & \multirow[t]{2}{*}{$\begin{array}{l}\text { Média } \\
\text { Mean }\end{array}$} \\
\hline & 10/07-20/07 & 21/07-17/08 & 18/08-14/09 & $15 / 09-12 / 10$ & 13/10-02/11 & \\
\hline SS & 0,522 & 0,750 & 0,925 & 0,782 & 0,587 & 0,751 \\
\hline S 0,5 & 0,722 & 0,849 & 1,052 & 0,837 & 0,899 & 0,894 \\
\hline $\mathrm{S} 1,0$ & 1,022 & 0,786 & 0,901 & 0,806 & 0,619 & 0,809 \\
\hline $\mathrm{S} 1,5$ & 0,644 & 1,044 & 0,992 & 1,155 & 0,566 & 0,936 \\
\hline Média & 0,728 & 0,857 & 0,968 & 0,895 & 0,668 & 0,848 \\
\hline Mean & & & & & & \\
\hline
\end{tabular}

Na Figura 1, são apresentados os valores observados e estimados pelas equações do GMD conforme os níveis de suplementação durante o período de pastejo. O valor de mínima significância entre as combinações NS*P foi de $0,396 \mathrm{~kg} / \mathrm{animal} / \mathrm{dia}$. O maior GMD verificado foi de $1,155 \mathrm{~kg} /$ animal/dia, obtido pelas novilhas S-1,5 no período de 14/09 a 12/10. O menor desempenho individual foi verificado no período de adaptação, 10 a 20 de julho, no qual as novilhas SS apresentaram GMD de 0,522 kg/animal/dia.

Novilhas suplementadas com $1 \%$ do PV, no período de adaptação, tiveram GMD de 1,022 kg/animal/dia, possibilitando incremento de 95,78\% sobre o GMD das não-suplementadas no mesmo período. Neste período, pode ter ocorrido baixo consumo de MS de forragem, em decorrência, principalmente, da baixa capacidade de ingestão das novilhas. No S-1,0, este fator foi compensado pelo consumo do suplemento, apresentando reflexos positivos sobre o GMD. Subprodutos com altas concentrações de fibra digestível, como é o caso do farelo de trigo, segundo Garcés-Yepez et al. (1997), têm mostrado efeitos associativos negativos menores sobre a digestão da fibra do que suplementos ricos em amido. No S-1,5, por outro lado, o maior tempo necessário à adaptação dos animais à alta quantidade de suplemento não possibilitou efeito aditivo sobre o desempenho animal neste período inicial.

No decorrer do período de pastejo, o desempenho individual das novilhas teve comportamento distinto para os níveis de suplementação. Os valores de GMD das novilhas SS e S-1,5 foram mais bem explicados pela regressão quadrática, com $\mathrm{R}^{2}$ de 0,702 e 0,660, respectivamente. Os GMD das novilhas S-0,5 e S-1,0, por sua vez, apresentaram grande oscilação durante o período de pastejo. O GMD das novilhas
S-0,5 não se ajustou em equações de regressão, isto é, não houve relação significativa entre o GMD e período de pastejo, fato que pode ser explicado pela pequena quantidade de suplemento fornecida. Quanto menor a quantidade de suplemento, maior a variação no consumo individual e, conseqüentemente, maior a variação no GMD (Rocha, 1999). O GMD das S-1,0 se ajustou à equação linear negativa $\left(R^{2}\right.$ de 0,351$)$. A redução no GMD durante o período de pastejo, neste tratamento, pode ser conseqüência da rápida ingestão do suplemento. A rapidez no consumo de suplemento pode aumentar a tendência para o aparecimento de acidose lática prejudicando o ganho de peso dos animais (Horn et al., 1995).

O GMD médio e o consumo de forragem estimado das novilhas SS, S- 0,5 , S-1,0 e S- 1,5 foram de 0,751 e 3,9; 0,894 e 3,7; 0,809 e 3,1; 0,936 kg/animal/dia e $3,3 \%$ do PV, respectivamente. As novilhas SS apresentaram consumo estimado de MS acima do verificado por Roso \& Restle (2000) de 3,43\% do PV com a mesma categoria, também em pastagem de aveia preta + azevém. Estes valores, no entanto, foram inferiores aos de 5,11 e 4,8 observados por Frizzo et al. (2003), quando novilhas receberam 0,7 do PV de farelo de arroz + polpa cítrica ou quando não foram suplementadas em pastagem de aveia e azevém.

O consumo estimado, no presente trabalho, embora superior ao colocado pelo NRC (1984) para animais desta categoria, 2,5\% do PV, mostra claramente os efeitos de adição e substituição do consumo de forragem pelo consumo de suplemento. A taxa de substituição foi de 0,4; 0,8 e 0,4 kg de forragem para cada kg de suplemento fornecido e o efeito aditivo sobre o consumo total de MS foi de 60, 20 e $60 \%$ para as novilhas S-0,5, S-1,0 e S-1,5, respectivamente. O suplemento concentrado, na maioria das vezes,

R. Bras. Zootec., v.33, n.6, p.2104-2113, 2004 (Supl. 2) 
provoca diminuição no consumo de forragem em pastagens de qualidade, como é o caso da aveia preta + azevém, porém o consumo total de MS, geralmente, é elevado (Hodgson, 1990). O menor efeito aditivo sobre o consumo total de MS verificado no tratamento S-1,0 afetou o GMD, pois possibilitou incremento de apenas 7,7\% sobre o GMD das novilhas SS e de 19,0 e 24,6\%, respectivamente, das novilhas S-0,5 e S-1,5.

A maior taxa de substituição verificada no $S-1,0$ pode ter sido influenciada pelo comportamento animal no consumo de suplemento. Enquanto as novilhas deste tratamento consumiam a quantidade oferecida imediatamente ao fornecimento do suplemento, as novilhas $\mathrm{S}-1,5$ retornavam ao cocho para a ingestão de parte de concentrado, em média, a cada duas horas. A distribuição do consumo do suplemento ao longo do dia mantém maior estabilidade do $\mathrm{pH}$ ruminal. Em trabalho com novilhas em milheto (Pennisetum americanum Leeke), Moraes et al. (2002) verificaram queda no $\mathrm{pH}$ ruminal de 6,5 para 5,5 na primeira hora após o fornecimento de suplemento na proporção de $1 \%$ do PV. A taxa de digestão da fibra é próxima da máxima com $\mathrm{pH}$ de 6,2-7,0 e cai bruscamente de maneira linear sob taxa de digestão zero, com pH 5,5-5,7 (Pitt et al., 1996). Os ruminantes podem compensar, parcialmente, a taxa de redução da digestão da fibra no rúmen pelo incremento no tempo de retenção de resíduos fibrosos neste compartimento; quando isto ocorre, o consumo de forragem diminui (Dixon \& Stockdadle, 1999).

O PV e a CC ao final do período de pastejo são de fundamental importância para estabelecer a idade ao primeiro acasalamento das novilhas. Os GMD obtidos proporcionaram PV final médio às novilhas SS, S-0,5, S-1,0, e S-1,5 de 246; 259; 252 e 264 kg, respectivamente. O peso mínimo recomendado pelo NRC (1996) para o primeiro acasalamento de novilhas é de $65 \%$ do peso adulto. Considerando-se o peso adulto do rebanho em questão de $450 \mathrm{~kg}$, portanto, ao final do período de pastejo, as novilhas SS, S-0,5, S1,0 e S1,5 apresentavam 54,7; 57,8; 56,0 e $58,7 \%$ do PV adulto e precisavam ganhar, em média, 47, 34, 41 e $29 \mathrm{~kg}$, respectivamente, até o período de acasalamento preconizado.

Constam na Figura 2 os valores observados e estimados pelas equações para condição corporal (CC), conforme os níveis de suplementação, durante o período de pastejo. O valor de mínima significância entre as combinações NS*P foi de 0,277 pontos. As novilhas S-0,5 e S-1,5 apresentaram ganhos de CC bastante semelhantes. Os valores estimados pelas equações lineares indicam que, a cada dia a mais de pastejo, as novilhas S-0,5 e S-1,5 apresentam ganho de CC de 0,0071 e 0,0072 pontos, respectivamente. A CC das novilhas S-1,0 foi mais bem representada pela equação quadrática, que mostra baixo ganho de CC nos primeiros 38 dias de pastejo, 10/07 a 17/08. No mesmo período, novilhas deste tratamento tiveram redução no GMD de 30,0\%, de 1,022 para 0,786 kg/ animal/dia (Figura 1). Em trabalho com vacas de descarte submetidas a níveis de suplementação energética em pastagem de inverno, de 0 a $0,8 \%$ do $\mathrm{PV}$, Restle et al. (2001) verificaram aumento linear na CC com o incremento do nível de suplementação.

O ganho de CC acumulado até o final do período de pastejo foi de 0,$5 ; 0,8 ; 0,7$ e 0,8 pontos para as novilhas SS, S-0,5, S-1,0 e S-1,5, respectivamente. A maior CC dos animais suplementados, ao final do período de pastejo, é determinada pela composição do ganho de peso. Animais recebendo suplementação energética em pastagens com elevado teor de proteína bruta tendem a acumular gordura mais precocemente em relação aqueles exclusivamente em pastejo (Frizzo et al., 2003; Pilau et al., 2002). A habilidade em alterar a condição corporal de animais em pastejo, segundo Poppi, citado por Poppi \& McLennan (1995), depende da obtenção de altas relações de proteína e energia nos nutrientes consumidos.

Na Figura 3, encontram-se os valores observados e estimados pelas equações de CA para os níveis de suplementação durante o período de pastejo. O valor de mínima significância entre as combinações NS*P foi de 402,99 kg/ha de PV.

A CA no tratamento SS variou de $629 \mathrm{~kg} / \mathrm{ha}$ de PV, no período de adaptação, a $1.004 \mathrm{~kg} / \mathrm{ha}$ de PV, no período final de pastejo, sendo mais bem representada pela equação quadrática $\left(R^{2}=0,799\right)$. A CA em sistemas de pastejo é extremamente dependente do teor, da produção e distribuição de MS da pastagem. A partir do momento em que houve redução na TAD (Tabela 1), de 54 para $29 \mathrm{~kg} / \mathrm{ha}$ de MS nos períodos de 18/08 a 14/09 e de 15/09 a 12/10, respectivamente, o incremento em CA caiu de 0,7 para $0,2 \%$ ao dia até o final do período de pastejo, ficando dependente apenas do aumento no teor de MS da pastagem de 13,69 para 23,22 \% (Tabela 2).

No tratamento S-1,5, por outro lado, a CA foi melhor representada pela equação linear $\left(R^{2}=0,844\right)$. Segundo os valores estimados, pode-se esperar 
aumento de 8,08 kg/ha de PV na CA a cada dia a mais no período de pastejo, a partir de CA inicial de $697 \mathrm{~kg} / \mathrm{ha}$ de PV. Considerando-se o consumo de forragem de $3,3 \%$ do PV e a taxa de substituição de $40 \%$, como discutido anteriormente, o fornecimento via suplemento de 31,25\% do consumo total de MS facilita a adequação da CA e, conseqüentemente, o manejo da pastagem. A estabilidade de produção é fator tão importante quanto a produção total de forragem, em virtude da dificuldade prática em trabalhar com carga animal variável (Roso \& Restle, 2000). Por outro lado, a grande vantagem em investir na suplementação em relação ao uso exclusivo da pastagem está no risco quase nulo ligado ao fornecimento do suplemento, pois a quantidade oferecida não depende de condições climáticas (Pötter et al, 2000).

A CA média do período de pastejo foi de 858; 864; 1.067 e $1.135 \mathrm{~kg} / \mathrm{ha}$ de PV nos tratamentos SS, S-0,5, $\mathrm{S}-1,0$ e S-1,5, respectivamente. As taxas de substituição dos tratamentos S-0,5 e S-1,5 foram semelhantes (40\%), entretanto, o incremento em CA foi pratica-

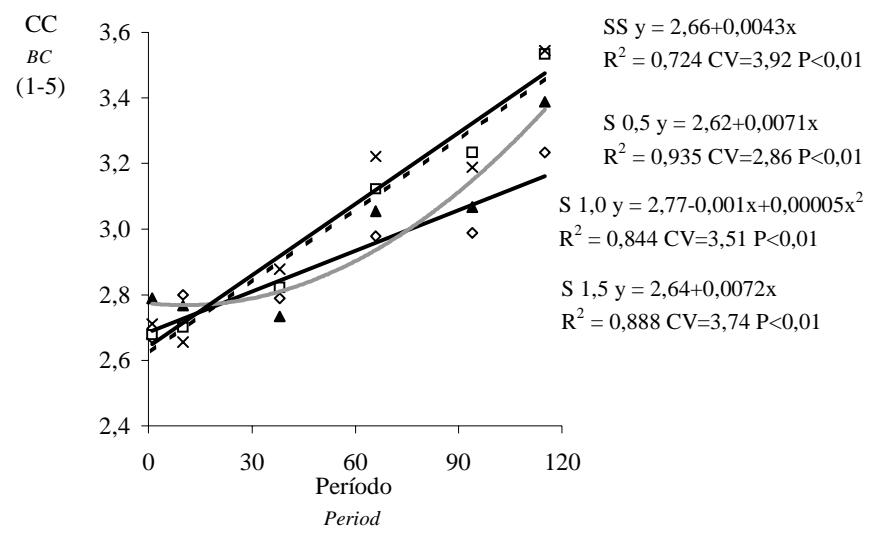

10/07-20-07 21/07-17/08 18/08-14/09 15/09-12/10 13/10-02/11

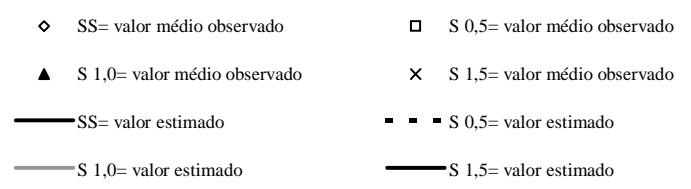

Figura 2 - Condição corporal (CC) de novilhas de corte submetidas a níveis de suplementação em pastagem de aveia preta + azevém, de acordo com o período de pastejo.

Figure 2 - Body condition $(B C)$ of beef heifers with different supplementation levels on oat + annual ryegrass pasture, according to grazing period.

R. Bras. Zootec., v.33, n.6, p.2104-2113, 2004 (Supl. 2) mente nulo (0,6\%) no S-0,5 e no S-1,5, de 32,2\% em relação ao SS. A mesma taxa de substituição verificada nos dois tratamentos, portanto, proporcionou incremento de CA apenas no S-1,5, em razão da maior quantidade de suplemento fornecida.

O ganho de peso vivo por área (GPA) obtido nos níveis de suplementação, durante o período de pastejo, encontra-se na Figura 4. O valor de mínima significância entre as combinações NS*P foi de $128,64 \mathrm{~kg} / \mathrm{ha}$ de PV. Os valores de GPA foram mais bem representados pela equação linear, que fornece GPA de 3,738; 3,927; 4,380 e 5,883 kg/ha/dia de PV. O investimento de 1,5\% do PV por dia em suplemento possibilitou maior GPA a partir de 70 e 81 dias de pastejo em relação ao uso exclusivo da pastagem e ao investimento em suplemento de $0,5 \%$ do PV por dia, respectivamente (GPA>128,64).

O período de utilização da pastagem é determinante sobre o GPA. Neste experimento, o GPA total foi de 404; 445; 519 e $626 \mathrm{~kg} /$ ha para os níveis SS, S-0,5, S-1,0 e S-1,5, respectivamente. Os

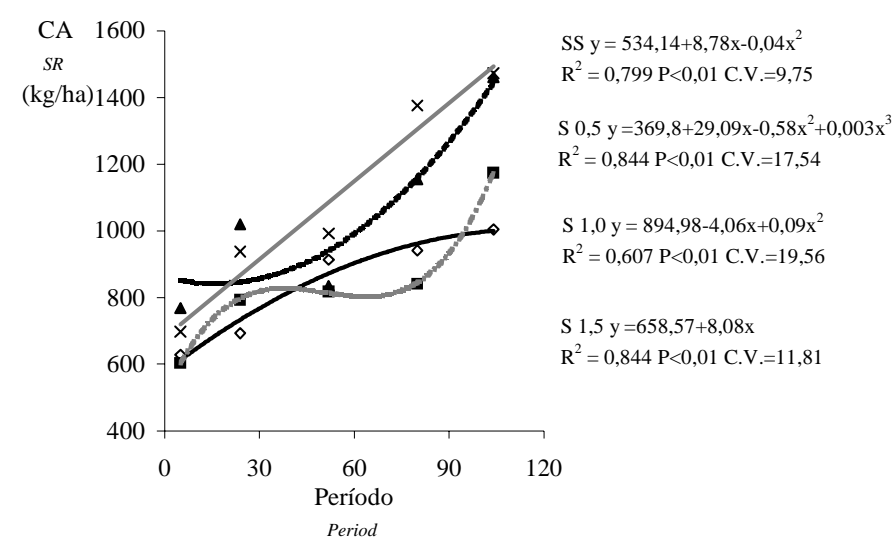

10/07-20/07 21/07-17/08 18/08-14/09 15/09-12/10 13/10-02/11

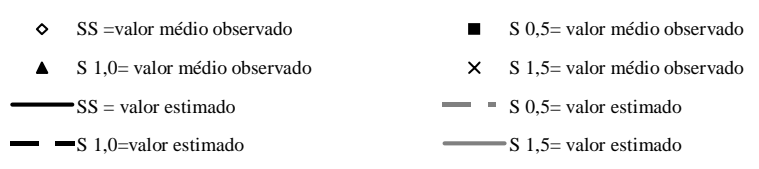

Figura 3 - Carga animal (CA) em pastagem de aveia preta + azevém com novilhas de corte submetidas a níveis de suplementação, de acordo com o período de pastejo.

Figure 3 - Stocking rate (SR) on oat + ryegrass pasture with beef heifers with different supplementation levels, according to the grazing period. 


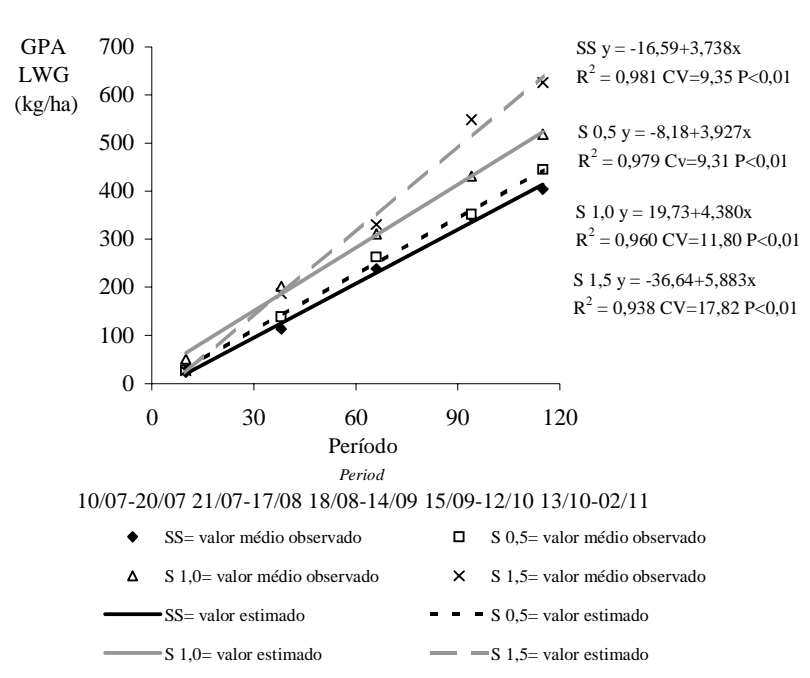

Figura 4 - Ganho de peso (GPA) em pastagem de aveia preta + azevém com novilhas de corte submetidas a níveis de suplementação, de acordo com o período de pastejo.

Figure 4 - Live weight gain (LWG) on oat + annual ryegrass pasture with beef heifers with different supplementation levels, according to grazing period.

valores observados são próximos aos verificados por Frizzo et al. (2003), trabalhando com novilhas previamente adaptadas, submetidas a níveis de suplementação de $0 ; 0,7 ; 1,4 \%$ do peso vivo, que obteve GPA de 433, 559 e 696 kg/ha, durante 98 dias de pastejo, respectivamente. Com períodos de utilização da pastagem superiores a 150 dias, são obtidos GPA superiores a $600 \mathrm{~kg} / \mathrm{ha}$ com novilhas exclusivamente em pastejo (Roso \& Restle, 2000).

\section{Conclusões}

A suplementação energética com farelo de trigo alterou a composição de ganho de peso dos animais e, consequentemente, acarretou maior ganho de condição corporal nas novilhas suplementadas.

Maior carga animal, sem redução no ganho de peso individual, em pastagem de aveia preta + azevém, foi obtida com animais recebendo 1,5\% do PV de farelo de trigo. Conseqüentemente, o maior ganho de peso vivo por área foi realizado neste mesmo nível de suplementação.

A resposta animal aos diferentes níveis de suplementação foi variável conforme o ciclo da pastagem, em conseqüência do consumo de matéria seca dos animais e dos parâmetros qualitativos da forragem.

\section{Literatura Citada}

ASSOCIATION OF OFFICIAL ANALYTICAL CHEMISTS AOAC. Official methods of analysis. 14.ed. Washington, D.C., 1984. 1141p.

DIXON, R.M.; STOCKDADLE, C.R. Associative effects between forages and grains: consequences for feed utilization. Australian Journal Agricultural Resarch, v.50, p.757773, 1999.

EMPRESA BRASILEIRA DE PESQUISA E AGROPECUÁRIA - EMBRAPA. Centro Nacional de Pesquisa de Solos. Sistema brasileiro de classificação de solos. Rio de Janeiro: Embrapa Solos, 1999. 412p.

FRIZZO, A.; ROCHA, M.G.; RESTLE, J. et al. Produção de forragem e retorno econômico da pastagem de aveia e azevém sob pastejo com bezerras de corte submetidas a níveis de suplementação energética. Revista Brasileira de Zootecnia, v.32, n.3, p.632-642, 2003.

GARCÉS-YEPEZ, P.; KUNKLE, W.E.; BOILES, D.B. Effect of supplemental energy source and amount of forage intake and performance by steers and intake and diet digestibility by sheep. Journal of Animal Science, v.75, n.7, p.1918-1925, 1997.

GIBB, M.J.; TREACHER, T.T. The effect of herbage allowance on herbage intake and performance of lambs grazing perennial ryegrass and red clover swards. Journal Agricultural Science, v.86, p.355-365, 1976.

HODGSON, J. Grazing management. Science into practice. Essex: Longman England, 1990. 203p.

HORN, G.W.; CRAVEY, M.D.; MCCOLLUM, F.T. et al. Influence of high-starch vs high-fiber energy supplements on performance of stocker cattle grazing wheat pasture and subsequent feedlot performance. Journal of Animal Science, v.73, n.1, p.45-54, 1995.

KLINGMANN, D.L.; MILES, S.R.; MOTT, G.O. The cage method for determining consumption and yield of pasture herbage. Journal of Society of Agronomy, v.35, p.739746, 1943.

LOWMAN, B.G.; SCOTT, N.; SOMERVILLE, S. Condition scoring beef cattle. Edinburgh: East of Scotland College of Agriculture, 1973. 8p.

LUPATINI, G.C.; RESTLE, J.; CERETTA, M. et al. Avaliação da mistura de aveia preta preta (Avena strigosa) e azevém (Lolium multiflorum) sob pastejo submetidas a níveis de nitrogênio. I-Produção e qualidade de forragem. Pesquisa Agropecuária Brasileira, v.33, n.11, p.1939-11943, 1998.

MORAES, A. Produtividade animal e dinâmica de uma pastagem de pangola (Digitaria decumbens stent), azevém (Lolium multiflorum Lam.) e trevo branco (Trifolium repens L.) submetida a diferentes pressões de pastejo. Porto Alegre: Universidade Federal do Rio Grande do Sul, 1991. 200p. Tese (Doutorado em Zootecnia) - Universidade Federal do Rio Grande do Sul, 1991.

MORAES, J.; GENRO, T.C.; SANCHEZ, L.M. et al. Parâmetros ruminais de bovinos em pastagem de recebendo ou não suplementação energética. In: REUNION DE GRUPO TECNICO EN FORRAJERAS DEL CONO SUR, 19, 2002, Mercedes. Anais... Mercedes: INTA, 2002. p.205.

MORENO, J.A. Clima do Rio Grande do Sul. Porto Alegre: Secretaria da Agricultura, 1961. 41p.

NATIONAL RESEARCH COUNCIL - NRC. Nutrient requirement of beef cattle. 6.ed. Washington, D.C.: National Academy Press, 1984. 90p. 
NATIONAL RESEARCH COUNCIL - NRC. Nutrient requirements of beef cattle. 7.ed. Washington, D.C.: National Academy Press, 1996. 242p.

PELLEGRINI, C.; ROCHA, M.G.; PILAU, A. et al. Características qualitativas de gramíneas de estação fria. In: REUNION DE GRUPO TECNICO EN FORRAJERAS DEL CONO SUR, 19., 2002, Mercedes. Anais... Mercedes: INTA, 2002. p.157.

PILAU, A.; ROCHA, M.G.; RESTLE, J. et al. Desenvolvimento corporal de novilhas de corte sob pastagem de aveia preta + azevém com e sem suplementação energética. In: REUNIÃO ANUAL DA SOCIEDADE BRASILEIRA DE ZOOTECNIA, 39., 2002, Recife. Anais... Recife: Sociedade Brasileira de Zootecnia, [2002]. CD-ROM. Forragicultura. FOR-1010.

POPPI, D.P.; McLENNAN, S.R. Protein and energy utilization by ruminants at pasture. Journal of Animal Science, v.73, n.1, p.278-290, 1995.

PITT, R.E.; Van KESSEL, J.S.; FOX, D.G. et al. Prediction of ruminal volatile fatty acids and $\mathrm{pH}$ within the net carboydrate and protein system. Journal of Animal Science, v.74, n.1, p.226-244, 1996.

PÖTTER, L.; LOBATO, J.F.P.; MIELITZ NETTO, C.G.A. Análises econômicas de modelos de produção com novilhas de corte primíparas aos dois anos, três e quatro anos de idade. Revista Brasileira de Zootecnia, v.29, n.3, p.861-870, 2000.

REARTE, D.H.; PIERONI, G.A. Supplementation of temperate pastures. In: INTERNATIONAL GRASSLAND CONGRESS, 19., 2001, São Pedro. Proceeding... São Pedro: SBZ, 2001, p.679-689.

RESTLE, J.; ROSO, C.; OLIVEIRA, A.N. et al. Suplementação energética para vacas de descarte de diferentes idades em terminação em pastagem cultivada de estação fria sob pastejo horário. Revista Brasileira de Zootecnia, v.29, n.4, p.1216-1222, 2000.

RESTLE, J.; VAZ, F.N.; ROSO, C. et al. Desempenho e características da carcaça de vacas de diferentes grupos genéticos em pastagem cultivada com suplementação energética. Revista Brasileira de Zootecnia, v.30, n.6, p.1813-1823, 2001.

RIBEIRO FILHO, H.M.; DELAGARDE, R.; PEYRAUD, J.L. et al. Inter-relação entre oferta de forragem e o comportamento ingestivo de vacas leiteiras sob um regime de pastoreio em faixas diárias. In: REUNIÃO ANUAL DA SOCIEDADE BRASILEIRA DE ZOOTECNIA, 39., 2002, Recife. Anais... Recife: SBZ, 2002. CD-ROM. Forragicultura. FOR-1115.
ROCHA, M.G. Suplementação a campo de bovinos de corte. In: LOBATO, J.F. (Ed.) Produção de bovinos de corte. Porto Alegre: PUCRS. 1999. p.77-96.

ROCHA, M.G.; RESTLE, J.; SANTOS, D.T. et al. Produção animal em sistemas intensivos de utilização da pastagem de aveia preta mais azevém. In: REUNIÃO ANUAL DA SOCIEDADE BRASILEIRA DE ZOOTECNIA, 38., 2001, Piracicaba. Anais... Piracicaba: Sociedade Brasileira de Zootecnia, 2001. p.191.

ROCHA, M.G.; LOBATO, J.F.P. Sistemas de alimentação pósdesmama de bezerras de corte para acasalamento com 14/15 meses de idade. Revista Brasileira de Zootecnia, v.31, n.4, p.1814-1822, 2002.

ROCHA, M.G.; RESTLE, J.; PILAU, A. et al. Produção animal e retorno econômico da suplementação em pastagem de aveia preta e azevém. Ciência Rural, v.33, n.3, p.85-93, 2003.

ROSO, C.; RESTLE, J. Aveia preta, triticale e centeio em mistura com azevém. 2. Produtividade animal e retorno econômico. Revista Brasileira de Zootecnia, v.29, n.1, p.85-93, 2000.

SANTOS, D.T.; ROCHA, M.G.; GENRO, T.C. Produção animal em pastagem cultivada com ou sem o uso de suplementos energéticos para bezerras de corte. In: REUNIÃO ANUAL DA SOCIEDADE BRASILEIRA DE ZOOTECNIA, 39., 2002, Recife. Anais... Recife: Sociedade Brasileira de Zootecnia, 2002. CD-ROM. Forragicultura. FOR-1511.

STATISTICAL ANALYSES SYSTEM - SAS. SAS/STAT user's guide: statistics. 4.ed. Version 6, v.2. Cary: 1997. 943p.

TILLEY, J.M.A.; TERRY, R.A. A two-stage technique for the in vitro digestion of forage crop. Journal of Bristish Grassland Society, v.18, n.2, p.104-111, 1963.

WILM, H.G.; COSTELLO, D.F.; KLIPPLE, G.E. Estimating forage yield by the double-sampling methods. Journal of American Society of Agronomy, v.36, p.194-203, 1944.

Recebido em: 19/05/03 Aceito em: 29/04/04 